\title{
Integrated biomimetic carbon nanotube composites for in vivo systems $\dagger$
}

\author{
Manoj Kumar Singh, ${ }^{* a}$ Jose Gracio, ${ }^{a}$ Philip LeDuc, ${ }^{b}$ Paula P. Gonçalves, ${ }^{c}$ Paula A. A. P. Marques, ${ }^{a}$ \\ Gil Gonçalves, ${ }^{a}$ Filipa Marques, ${ }^{c}$ Virgília S. Silva, ${ }^{c}$ Fernando Capela e Silva, ${ }^{d}$ Joana Reis, ${ }^{e}$ José Potes ${ }^{e}$ \\ and António Sousa ${ }^{a}$
}

\author{
Received 5th April 2010, Accepted 30th June 2010 \\ DOI: 10.1039/c0nr00237b
}

\begin{abstract}
As interest in using carbon nanotubes for developing biologically compatible systems continues to grow, biological inspiration is stimulating new directions for in vivo approaches. The ability to integrate nanotechnology-based systems in the body will provide greater successes if the implanted material is made to mimic elements of the biological milieu especially through tuning physical and chemical characteristics. Here, we demonstrate the highly successful capacity for in vivo implantation of a new carbon nanotube-based composite that is, itself, integrated with a hydroxyapatite-polymethyl methacrylate to create a nanocomposite. The success of this approach is grounded in finely tailoring the physical and chemical properties of this composite for the critical demands of biological integration. This is accomplished through controlling the surface modification scheme, which affects the interactions between carbon nanotubes and the hydroxyapatite-polymethyl methacrylate. Furthermore, we carefully examine cellular response with respect to adhesion and proliferation to examine in vitro compatibility capacity. Our results indicate that this new composite accelerates cell maturation through providing a mechanically competent bone matrix; this likely facilitates osteointegration in vivo. We believe that these results will have applications in a diversity of areas including carbon nanotube, regeneration, chemistry, and engineering research.
\end{abstract}

\section{Introduction}

Carbon nanotubes (CNTs), with their unique and fascinating one-dimensional nanostructure, are becoming increasingly important for their use in novel development directions for groundbreaking biomedical applications. Of significant biological importance when utilizing this technology is to exercise control over mechanical properties at the material-biological interface. ${ }^{1}$ Manipulation of mechanical properties within these systems can dictate cell response and affect many physiological responses. ${ }^{2,3} \mathrm{CNTs}$ have already been employed in the mechanics of materials domain for decades because of their high strength, which makes them ideal for a variety of applications including polymeric composite systems. Their successes in vivo though have been inhibited by physiological challenges as the promise of introducing pristine nonfunctionalized CNTs in polymer matrixes has been limited because this type of nanomaterial is practically insoluble and can accumulate in cells, organs, and tissues with dangerous effects. ${ }^{4,5}$ This problem has been

${ }^{a}$ Nanotechnology Research Division, Center for Mechanical Technology \& Automation, University of Aveiro, 3810-193 Aveiro, Portugal. E-mail: mksingh@ua.pt; Fax: +351234370953; Tel: +351234370827

${ }^{b}$ Carnegie Mellon University, Department of Mechanical Engineering, 415 Scaife Hall, 5000 Forbes Avenue, Pittsburgh, PA, 15213, USA

${ }^{c}$ CESAM, Center for Environmental and Marine Studies, Department of Biology, University of Aveiro, 3810-193 Aveiro, Portugal

${ }^{d}$ Institute for Agrarian and Environmental Sciences, Department of Biology, University of Évora, 7002-554 Évora, Portugal

${ }^{e}$ Research Centre for Health Technologies and Sciences, Department of Veterinary Medicine, University of Évora, 7002-554 Evora, Portugal

$\dagger$ Electronic supplementary information (ESI) available: Additional figures. See DOI: $10.1039 / \mathrm{c} 0 \mathrm{nr} 00237 \mathrm{~b}$ overcome, however, by chemically modifying the surfaces of the CNTs, which addresses the solubility challenges in most solvents and polymers. ${ }^{6-8}$

Modifying the surface properties can introduce trade-offs between the design ability and the implantation success. From a mechanics perspective the atomically smooth surface of nanotubes that reduces interfacial bonding creates a challenge, as the load transfer is then limited between the matrix and the CNTs. This surface and mechanics related issue is a result of intrinsic Van der Waals forces, which is further complicated by the fact that nanotubes have very low solubility in most solvents and are typically found in bundles. When mixed into a polymeric matrix, CNTs tend to be entangled agglomerates, and homogeneous dispersions are not easily obtained which directly affects the mechanical properties. In previous work we have facilitated CNT dispersion while reducing the aggregation by integrating carboxylic functionalized CNTs in a polymethyl methacrylate (PMMA) matrix through a freeze granulation technique, ${ }^{9}$ which indicates that the surface interactions are important and can be controlled. The interfacial interaction between CNTs and polymers and the ability to disperse them homogeneously throughout a matrix are critical factors toward fully utilising the extraordinary properties of CNTs.

For developing a biologically inspired composite system, there are numerous available composite materials. One particular area that has shown promise is in using bone cements such as PMMA. PMMA has been extensively used in orthopaedic surgery as a biomaterial that fixes artificial joints to bone and fills bone defects, as well as a drug-delivery system. ${ }^{10}$ One well documented issue with bone cements is that the fixation strength of PMMA cement to bone is primarily dependent on mechanical 
characteristics. To address this, a complementary material, hydroxyapatite (HA), has been used with PMMA. HA is a prime constituent of bone cements and is particularly useful for a range of reasons including its ability to bond chemically with living bone tissues as well as its chemical and crystalline similarity to human skeletal apatite. These systems alone though exhibit intrinsic brittleness and poor strength, thus restricting its clinical applications under load-bearing conditions. ${ }^{11-14}$ The ability to develop CNT composites holds great promise for producing high-strength biomaterials, in particular those to be positioned in close contact with bones, such as prostheses for arthroplasty, plates or screws for fracture fixation, drug delivery systems, and scaffolding for bone regeneration. ${ }^{15,16}$ Providing enhanced mechanical properties is critical for these approaches to be successful as failure of material systems leads directly to deleterious consequences. Although this is an advantageous property, controlling the mechanical properties is not a simple task due to mixing and surface interaction issues.

Our approach is based on inspiration from the biological domain where controlling both physical and chemical interactions are critical for producing a highly compatible system. We believe that there are at least two key integrated components that need to be achieved: (i) the composite biomaterial must mimic the mechanical behaviour of the tissue to be replaced, and; (ii) it must be able to form a steady interface to assist remodeling of bone tissue. In this context, biocompatibility in bone is a very important component given that recovering from trauma is a complex process that involves the activation and formation of osteoblastic cells from undifferentiated mesenchymal osteoprogenitor cells, synthesis of a new organic matrix, and absorption of the preexisting matrix in the injured bone. To address this, one must accelerate the rate of bone fracture healing such that the fixation mechanisms and materials used provide controlled mechanical stress at the interface between tissue and the implant. This is believed to accelerate the activity of bone cells that are key regulating agents of bone-response to implanted materials. ${ }^{17}$ Here, we developed a new CNT-based composite integrated with hydroxyapatite-polymethyl methacrylate (HA/PMMA) with controlled physical and chemical properties (Fig. 1). We implanted the composite in bone and observed significantly improved biocompatibility. Next, the mechanical properties of this composite were determined relative to the surface functionalization that we imposed on the CNTs for the composite. We then analyzed the cellular response to these composites to understand the in vitro response, which contributed to the successful in vivo implantation.

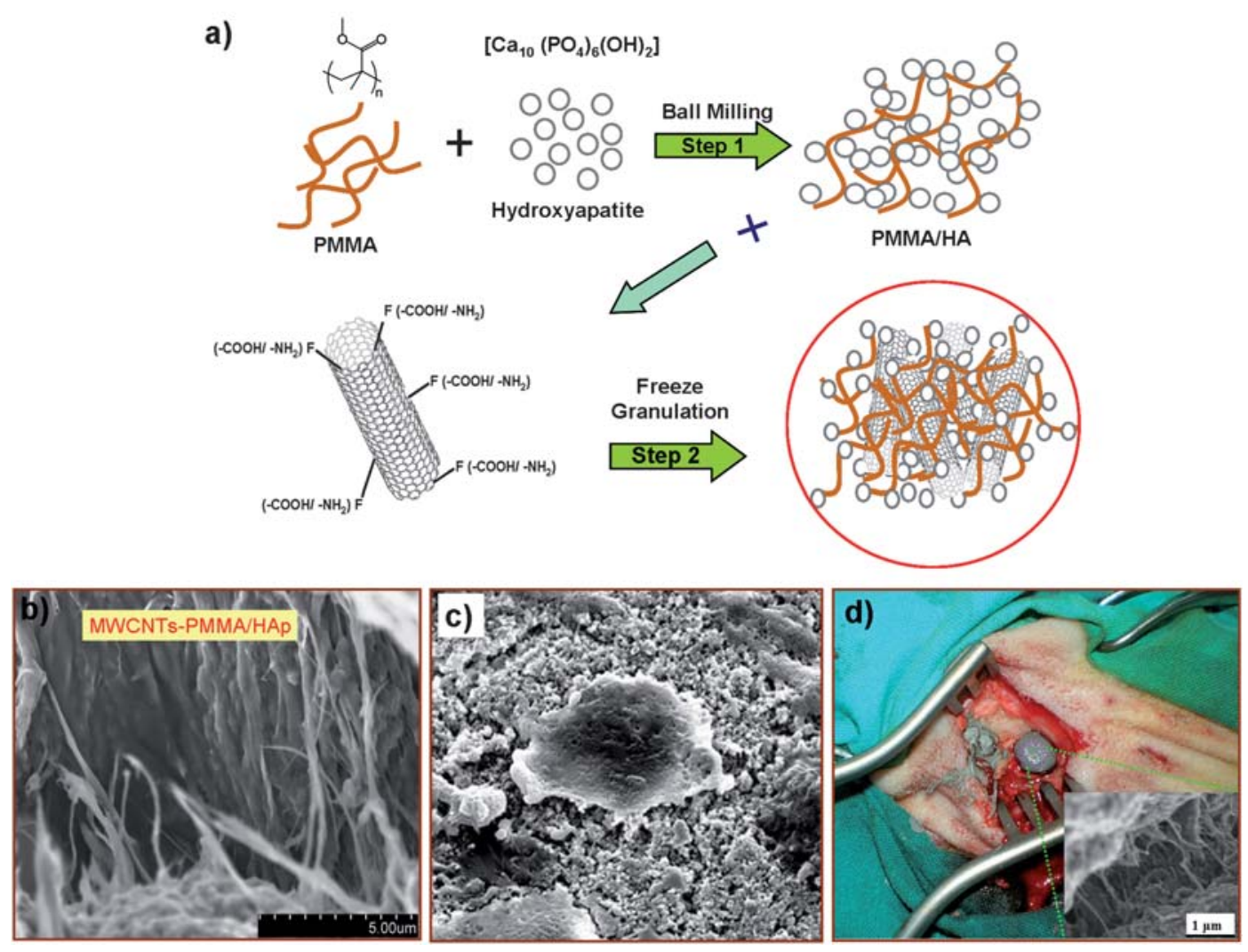

Fig. 1 Schematic diagram for the synthesis and biological testing of a chemically modified MWCNT-reinforced PMMA/HA nanocomposite. (a) A twostep approach is used to generate this nanocomposite. In the first step, a homogenous mixture of HA powder and PMMA was prepared by ball milling. In the second step, this solution was mixed with $0.1 \mathrm{wt} \%$ of functionalized MWCNTs (both with $-\mathrm{COOH} / \mathrm{or}-\mathrm{NH}_{2}$ ) through freeze-granulation. Through this technique, the material homogeneity was preserved and the dispersion of the carbon nanotubes was enhanced in the composite matrix. For the in vivo and in vitro studies, a mixture of the monomer solution of the bioactive bone cement and dry powder of the MWCNT-reinforced PMMA/HA nanocomposite was prepared. (b) A SEM image of $0.1 \%$ COOH-MWCNT/PMMA/HA nanocomposite paste. (c) SEM image of MG63 cells growing on the HA-PMMA- $0.1 \%$ COOH-MWCNT nanocomposite. (d) Digital image of filling the bone during the surgical procedure with the bioactive bone cement paste in three holes of a sheep tibia. 


\section{Experimental section}

\section{Creation of carbon nanotube composites}

1.1 Dispersion of covalent or noncovalent functionalized multiwalled carbon nanotubes (MWCNTs-COOH/or - $\mathbf{N H}_{2}$ ) in water. Commercially available (purity $>95 \%$, Nanocyl-3150) MWCNTs with lengths of $1-5 \mu \mathrm{m}$ and diameters of 5-10 nm were suspended in a $3: 1$ mixture of concentrated $\mathrm{H}_{2} \mathrm{SO}_{4}$ $(18.4 \mathrm{M}) / \mathrm{HNO}_{3}(16 \mathrm{M})$ and sonicated in a water bath for $24 \mathrm{~h}$. The resulting suspension was then diluted with deionized water, and the MWCNTs were collected on a $100 \mathrm{~nm}$ pore membrane filter before being washed with deionized water. Based on the established procedure for noncovalent functionalization of CNTs with pyrenyl compounds, ${ }^{18} 300 \mathrm{mg}$ of these MWCNTs were sonicated in a $200 \mathrm{~mL}$ ethanol solution containing $300 \mathrm{mg}$ of 1-aminopyrene (purity $>99 \%$, Sigma Aldrich) for $2 \mathrm{~h}$ in nitrogen atmosphere. This mixture was stirred overnight. Subsequently, the amino-MWCNTs were collected on a $100 \mathrm{~nm}$ pore membrane filter and washed with deionized water. The resultant covalent or noncovalent functionalized multiwalled carbon nanotubes were analyzed using FTIR (Nicolet AVATAR-360 FT-IR spectrophotometer) (see Fig. 3a).

1.2 Freeze-granulation technique to produce PMMA and HA nanocomposites with well dispersed functionalized MWCNTs. The homogenous solution of $0.1 \mathrm{wt} \%$ of functionalized MWCNTs (both with $-\mathrm{COOH} /$ or $-\mathrm{NH}_{2}$ ) in water was mixed with a combination of commercially available PMMA (high viscosity bone cement purity $>99 \%$, Johnson and Johnson Co.) and HA (particle size $2-3 \mu \mathrm{m}$ with purity $>98 \%$, Agoramat-Advanced Materials) at a 1:2 weight percentage. This homogenous mixture of HA powders and PMMA was prepared by ball milling. ${ }^{19}$ There is no effect on HA powder size distribution during ball milling as the ball milling inhibits the agglomeration of HA powder during the mixing of PMMA with HA.

The freeze-granulation technique (Power Pro Freeze-granulator L5-2, Sweden) dried the nanocomposite of functionalized MWCNT-reinforced PMMA/HA powder, preserved the material homogeneity, and enhanced the dispersion of the carbon nanotubes in the composite matrix. ${ }^{9}$ Fig. 1 shows a schematic diagram for the step-by-step procedure for creating the MWCNT-reinforced PMMA/HA nanocomposites. Granules with no cavities can be created, and, since no migration of small particles was possible, a high degree of granule homogeneity can be produced while the mild drying avoids oxidation of the powder. ${ }^{20}$ Also, lower granule density and evenly distributed low concentrations of MWCNTs allowed for softer granules with a wider granule size distribution. The freeze-dried nanoparticles were then collected and dried in vacuum for 3 days. In order to remove any remaining liquid, the nanocomposite was placed in an oven at $40{ }^{\circ} \mathrm{C}$ for $24 \mathrm{~h}$.

\section{Surface characterization and mechanical properties}

\subsection{Experimental surface characterization}

2.1.1 FE-SEM. Field-emission scanning electron microscopy (Hitachi S-800, and SU-70, $30 \mathrm{keV}$ ) was performed to study the dispersion and distribution of the functionalized MWCNTs (both with - $\mathrm{COOH}$ /or $-\mathrm{NH}_{2}$ ) in the PMMA modified
HA matrix. The phase composition and purity of the samples were determined with a Philips Xpert-MPD X-ray powder diffractometer with $\mathrm{Co} \mathrm{K} \alpha$ radiation at $45 \mathrm{kV}$ and $40 \mathrm{~mA}$. Room temperature micro-Raman studies were also performed to study the integration of MWCNTs with the PMMA-HA nanocomposite material.

\subsection{Determination of mechanical properties}

2.2.1 MTS Nano Indenter XP. Nanoindentation tests were performed using an MTS Nano Indenter XP with a Berkovich diamond tip. ${ }^{21}$ Hardness and elastic modulus of the PMMA/HA nanocomposite with different percentages of MWCNTs were measured as a function of the indentation depth using a continuous stiffness measurement (CSM) method. The typical nanoindentation test consisted of seven subsequent steps: 1) approaching the nanocomposite surface; 2) determining the contact point; 3) loading to the peak load; 4) holding the tip for $10 \mathrm{~s}$ at the peak load; 5) unloading $90 \%$ of the peak load; 6 ) holding the tip for $100 \mathrm{~s}$ at $10 \%$ of the peak load to compensate for the thermal drift correction; and, 7) unloading the nanocomposite completely. The hardness and elastic modulus from these experiments were obtained through the Oliver-Pharr method. ${ }^{22}$

\section{In vivo methods}

3.1 Animal model. Following the experimental protocol approved by the National Ethics Committee for Laboratory Animals (Portugal), ${ }^{23}$ two healthy, adult male sheep with average weight of $45 \mathrm{~kg}$, were used for the in vivo implantation. The sheep were permanently housed indoors in group housing and were kept under a constant photoperiod cycle (light: from $07: 00$ to 19 : $00 \mathrm{~h}$; dark: from $07: 00$ to $19: 00 \mathrm{~h})$, temperature $\left(20 \pm 2{ }^{\circ} \mathrm{C}\right)$ and humidity $(50 \pm 10 \%)$. Food was withdrawn $36 \mathrm{~h}$, and water $6 \mathrm{~h}$ prior to anaesthesia.

3.2 Anaesthetic and surgical method. Surgery was performed under general anaesthesia, which was induced with pentobarbital through intravenous injection; the animals had been previously premedicated with xilazine and buprenorphine. The anaesthesia was maintained through using isoflurane administered with an endotracheal tube and spontaneous ventilation. An electrocardiogram (ECG) monitor and a pulsioximeter were used to monitor the condition of the animals. The antibiotherapy was initiated during surgery with amoxicillin (Clamoxyl) and these therapies were maintained for one week. The site of the surgery was prepped with a solution of Betadine (povidone-iodine) and alcohol (Dura-Prep; 3M Health Care, St. Paul, MN) after the animals were locally shaved. For the implantation of the bioactive bone cement in the tibia, the animals were placed in a dorsal recumbency position and a longitudinal incision was made on the frontal surface of the left and right tibia. After exposure of the tibial bone, the periosteum was reflected and a $2.5 \mathrm{~mm}$ diameter pilot hole was made with a surgical drill and then enlarged with low speed drilling to a $3.0 \mathrm{~mm}$ diameter. During the process, the bone was continuously perfused with a sterile saline solution. Three holes were drilled on each tibia as shown in Fig. S1 (see Supplementary Information $\dagger$ ) and then the holes were filled with the bioactive bone cement paste (Fig. 1d). 
The surgery field was covered with subcutaneous tissue and the skin was closed using absorbable Surgicryl @ 2-0 sutures.

3.3 Radiological and histological studies. Post-operative $\mathrm{X}$-ray tests were performed with a Mammodiagnost UC system (Philips) with 28 kV, $25 \mathrm{~mA}$, using coarse focus and Kodak Min$\mathrm{R}$ Screen film. Twelve weeks after implantation, the animals were sacrificed with an intravenous dose of sodium pentobarbital (Eutasil@). The implanted materials and the surrounding tissue was removed. The bone specimens for the histological evaluation were fixed in $4 \%$ buffered formaldehyde, dehydrated in graded alcohols and embedded in methyl methacrylate (Merck Supplier Part: 8.00590.1000). After polymerization, non-decalcified $30 \mu \mathrm{m}$ sections were obtained in the transversal direction using a saw microtome (Leica 1600) and then ground with silicon carbide powder. Thin sections were prepared of each specimen for evaluation by light microscopy (Eclipse 600, Nikon Japan). The bone sections were stained with toluidine blue. ${ }^{24,25}$

\section{In vitro methods}

4.1 Cell culture. The MG63 cell line, derived from human bone osteosarcoma, was used for direct contact assays. MG63 cells were grown in Alpha Minimum Essential Medium ( $\alpha$-MEM, Gibco) containing 10\% fetal bovine serum (FBS), $2.5 \mu \mathrm{g} \mathrm{mL}^{-1}$ fungizone, $100 \mathrm{U} \mathrm{mL}^{-1}$ penicillin-streptomycin and $85 \mu \mathrm{g} \mathrm{mL}{ }^{-1}$ gentamicin. ${ }^{26}$ During routine propagation, the cells were maintained in $75 \mathrm{~cm}^{2}$ Nunc Easy Flasks at $37{ }^{\circ} \mathrm{C}$ in humidified atmosphere containing $5 \% \mathrm{CO}_{2}$ for $3-4$ days. Then, the cells were removed by applying a trypsin-EDTA solution and seeded on the disk shaped composite samples at $1.5 \times$ $10^{-5}$ cells $\mathrm{mL}^{-1}$ in 12-well polystyrene culture plates, using the same culture conditions. In the control cultures, the cells were cultured in 12-well polystyrene culture plates at the same density as on the samples. Media were changed either every 2-3 days or $24 \mathrm{~h}$ prior to analysis.

4.2 Cell viability/growth/morphology assays. The determination of cell growth and viability of cell cultures was performed by analyzing cell cultures after staining with trypan blue (vital dye exclusion method) and by measuring the activity of living cells via mitochondrial dehydrogenase activity (3-[4,5-dimethylthiazol-2yl]-2,5-diphenyl tetrazolium bromide, MTT, based spectrophotometric method). The viability analyzer, Vi-CELL ${ }^{\mathrm{TM}} \mathrm{XR}$, Beckman Coulter, was used for the trypan blue dye exclusion method in cell suspensions obtained after trypsinization. Fifty real time images were collected per sample and the number of living and dead cells was recorded per frame to calculate the cell concentration and viability. These images also were used to construct distribution plots of average cell diameter and circularity $(\sqrt{4 A / \pi} / P / \pi$, where $A$ and $P$ represent the pixel cell area and perimeter, respectively). The "Cell growth determination kit MTT-based" from SIGMA was employed to assess cell viability directly in the 12 -well polystyrene plates. Both methods were conducted according the manufacturer instructions.

4.3 Alkaline phosphatase (ALP) activity. The treatment of cell cultures to quantify the activity of alkaline phosphatase, a typical representation of osteogenic activity of osteoblasts ${ }^{27,28}$ was similar to that described previously. ${ }^{29,30}$ Briefly, the medium of each well was collected to analyze secreted ALP, whereas cellular ALP was quantified after a 5 min lysis of the cell cultures, which were rinsed once with phosphate buffered saline (PBS), using $0.1 \%$ Triton X-100 (v/v) in $25 \mathrm{mM} \mathrm{Na}_{2} \mathrm{CO}_{3}(\mathrm{pH} 10.3)$. Lysates remained in the culture conditions in reaction medium for $2 \mathrm{~h}$ and then the reactions were stopped by adding $2 \mathrm{M}$ $\mathrm{NaOH}$. Both secreted and cellular ALP activities were measured spectrophotometrically, using $15 \mathrm{mM} p$-nitrophenol phosphate ( $p$ NPP) as the substrate in alkaline reaction medium ( $\mathrm{pH} 10.3)$ containing $2.5 \mathrm{mM} \mathrm{MgCl}$, at $37{ }^{\circ} \mathrm{C}$. The enzyme activity was determined by measuring the increase in absorbance at $410 \mathrm{~nm}$ accompanying the production of $p$-nitrophenol with a molar absorption coefficient of $1.73 \times 10^{-4} \mathrm{M}^{-1} \mathrm{~cm}^{-1}$ and normalized by the number of cells.

4.4 Data analysis. Statistical analysis was performed using Student's $t$-test. Data are reported as mean \pm standard error (S.E.) and $P$ values $<0.05$ were considered to be significant.

\section{Results and discussion}

The first critical step in developing this approach was to analyze the response of the CNT-reinforced HA/PMMA nanocomposites. These nanocomposites were derived via a two-step process (Fig. 1a). In the first step, a homogenous mixture of HA powder and PMMA was prepared by ball milling. The second step consisted of mixing this combination with a homogenous solution of $0.1 \mathrm{wt} \%$ of functionalized MWCNTs (both with $-\mathrm{COOH} /$ or $-\mathrm{NH}_{2}$ ). The MWCNT solution was introduced into water using a freeze-granulation technique, which allowed us to preserve the material homogeneity and enhance the dispersion of the CNTs in the composite matrix (Fig. 1b). After creating these nanocomposites, determining their in vitro and in vivo (Fig. 1c and $1 \mathrm{~d}$ ) response was essential. ${ }^{31}$

To examine the in vivo response with the nanocomposites, $\mathrm{X}$-ray tests were performed. After twelve weeks the inflammatory reactions in the surrounding tissues were examined. X-rays of the left tibia were captured immediately after surgery (Fig. 2i) and then after 12 weeks (Fig. 2ii). The drilled cavities, as indicated by an asterisk in Fig. 2(i) and (ii), had been invaded by the marrow region. Also, there were no signs of periosteal or bone negative reactions twelve weeks after implantation. Fig. 2(iii-vi) provided a histological evaluation of the stained specimens obtained twelve weeks after implantation. The periosteum covering the outer surface of the implant and the cortical bone at the interface did not show any adverse reaction to the implants (Fig. 2iii,iv). Furthermore, the contact between the cement and the bone showed no fibrous tissues or inflammatory cells as observed in Fig. 2iii. Osteocytes (denoted by red dotted circle in Fig. 2iii) were clearly observed. At higher magnifications, a favourable interface between bone and the cement was observed (Fig. 2iv). However, in the areas where there was no direct contact between the bone and the implant, osteoclast-like cells ${ }^{32}$ appeared on the cement surface (indicated by the green dotted circle in Fig. 2v). Furthermore, in our specimens (Fig. 2vi), new bone (B) clearly penetrated the pores of the bone cement $(\mathrm{C})$, as indicated by the green dotted arrow. The biocompatibility and osteoconductivity 

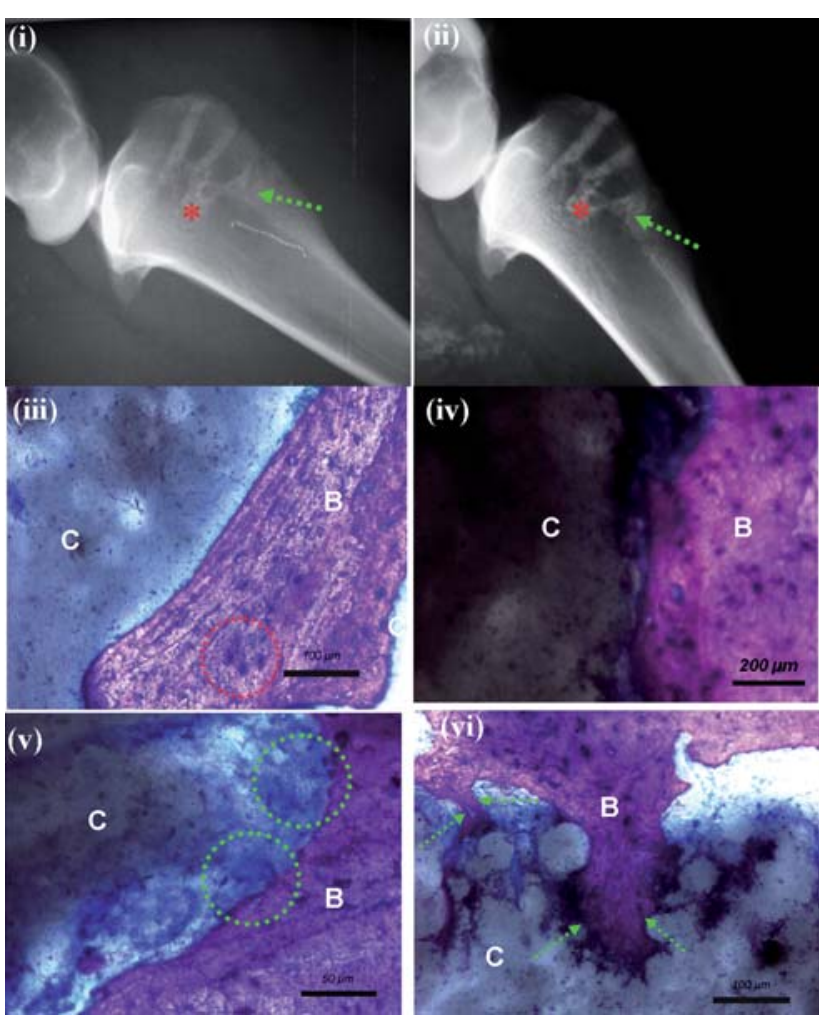

Fig. 2 In vivo response with the nanocomposite bone cement in sheep. (i) X-rays (left tibia) immediately after surgery and (ii) after 12 weeks. Invasion of the marrow region (indicated by the asterisk) and restoration of the cavities is observed. There are no inflammatory reactions in the surrounding tissues after 12 weeks. (iii) An image of Giemsa surface staining of the specimens at 12 weeks after implantation shows excellent contact between the nanocomposite PMMA-HA-CNT bioactive-bone cement (C) and the bone tissue (B) with no fibrous tissues and no inflammatory cell infiltration. Oteocytes, which are indicated by the red dotted circle regions, are observed. (iv) An image of Giemsa surface staining focusing on the interface between the nanocomposite bioactive bone cement and the tissue (C) and the bone tissue (B), which is very favourable. (v) An image of Giemsa surface staining focusing revealing multinuclear osteoclast-like cells covering the surface of the bone cement, as indicated by the green dotted circles; there was no direct contact between bioactive-bone cement (C) and bone tissue (B) generally observed. (vi) An image of Giemsa surface staining focusing showing that the new bone (B) clearly enters into the pores of the bone cement (C), as indicated by the green dotted arrow.

are critical factors as foreign material reside in vivo. A postmortem examination of the tibias revealed that the implants were completely covered by the periosteum. This finding was determined by fixing the regional lymph nodes with $4 \%$ formaldehyde, embedding them in paraphin, and then cutting them into $30 \mu \mathrm{m}$ sections with a microtome (Leica, Jung RM 2045). The specimens were stained with hematoxylin/eosin to examine the biocompatibility and osteoconductivity responses. The histological response of the regional lymph nodes revealed no significant morphologic changes in the regional lymph nodes between the control and test groups. The histological evaluations demonstrate that the CNT-reinforced composite with the bioactive bone cement responded favourably as a tibial bone implant based on its osteoconductivity and biocompatibility results. This biocompatibility has been demonstrated for an extended time period of 12 week post-operation for our $0.1 \%$ MWCNT-PMMA/HAp nanocomposites.

Examining the mechanical properties of these nanocomposites was also essential for in vivo successes in implantation since mimicking mechanical properties in materials is essential to biological response. ${ }^{1}$ While surface functionalization has gained much attention recently with respect to biocompatibility issues, the functionalization can also influence mechanical properties of these composites. ${ }^{9,33}$ Previously, the surfaces have been modified $^{34,35}$ although even with these approaches, delamination under fatigue has occurred until CNTs were integrated into the composite. ${ }^{9}$ Even with surface modifications, such as producing amine groups at the surface of the CNTs, increasing CNT concentrations beyond $1 \%$ did not appear to measurably improve the mechanical properties. ${ }^{36}$ In addition, while the incorporation of CNTs in living systems has been the subject of numerous studies, functionalizing CNTs has produced significant promise toward addressing concerns. To study this link between surface functionalization and mechanical properties, we functionalized CNTs (Fig. 3a) and then used a nanoidentation technique (MTS Nano Indenter XP with a Berkovich diamond tip) to study their resulting mechanical properties when imbedded in PMMA/HA nanocomposite (Fig. 3b-d). The composite responses were probed with CNTs, without CNTs, and with controlled surface functionalizations. In our experiment we have modified the surface of MWCNTs with bifunctional molecules
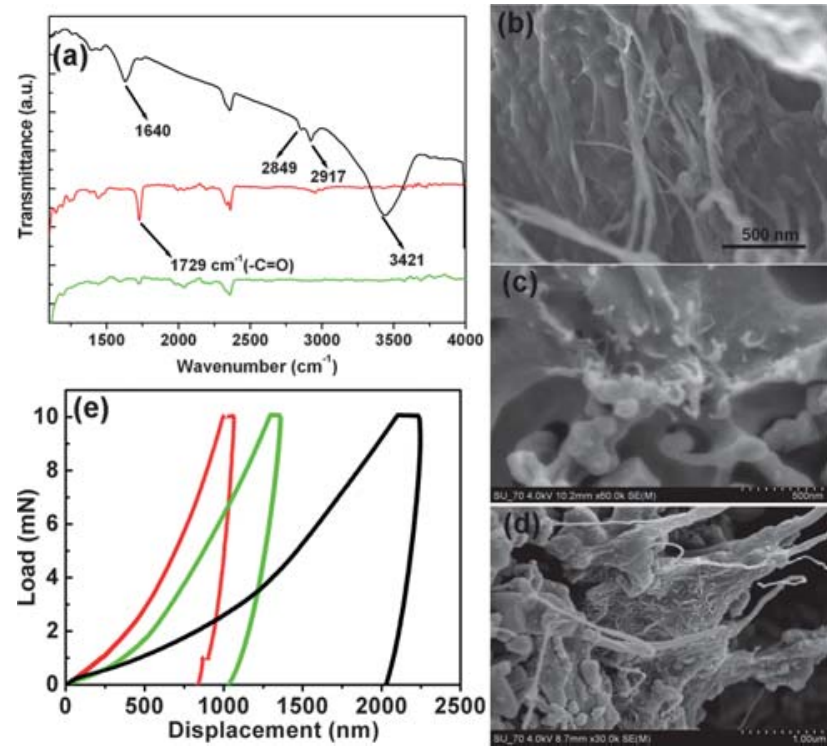

Fig. 3 Surface characterization and mechanical properties of the nanocomposite bone cement. (a) FTIR spectra for carboxylated (red), amine (black), and pristine (green) MWCNTs. The band at $1729 \mathrm{~cm}^{-1}$ is attributed to the carboxylated group as MWCNTs are functionalized with the $-\mathrm{COOH}$ group. Similarly, peaks at $1640 \mathrm{~cm}^{-1}$ and $3421 \mathrm{~cm}^{-1}$ correspond to $\mathrm{NH}_{2}$. These functional groups are absent though for unmodified MWCNTs. SEM images of (b) carboxylated, (c) amine, and (d) non-functionalized MWCNT-reinforced PMMA/HA nanocomposites. (e) Representative load-displacement curves at a peak indentation load of $10 \mathrm{mN}$ for the PMMA-HA with $0.1 \%$ carboxylated (red), amine (blue) and non-functionalized (green) MWCNTs. 
(1-aminopyrene) using the well-known noncovalent interactions between the pyrenyl groups of 1-aminopyrene and the sixmembered carbon rings of the nanotubes. On the other hand carboxylic acid $(\mathrm{COOH})$ are direct sidewall reactions (covalently bonded with CNTs).

The hardness and elastic modulus values as a function of the indentation depth for PMMA/HA and its $0.1 \%$ MWCNTs reinforced samples were found through analyzing loaddisplacement curves at a peak indentation load of $10 \mathrm{mN}$ (Fig. 3e). Thirty-two nanoindentation tests were conducted on each sample to determine the average hardness and elastic modulus for these composites (Table 1). From Table 1, the PMMA/HA with $0.1 \%$ COOH-functionalized MWCNTs (Fig. 3b) exhibited a significantly higher hardness (3.5 GPa) and elastic modulus (69 GPa). The $\mathrm{NH}_{2}$-functionalized MWCNTs had similar mechanical properties as the samples lacking functionalized MWCNTs. We assume that during the composite preparation an internal stress occurs between functional group and carbon nanowall surface, which results in the release of some CNTs and some agglomeration that behaves like defects in the matrix, which was observed Fig. 3c and 3d. In addition, from a visual examination of the SEM images, these nanocomposites displayed a significant amount of creep strain at the peak load and did not exhibit cracks formed during indentation. Investigating the holding segment at the peak load is an important component as the dissipation of creep displacement in most polymeric biomaterials and tissues often exhibits similar responses in terms of time-dependent or viscoelastic behaviour. ${ }^{37,38}$ This is important as bone is also a natural composite that exhibits viscoelastic behaviour. Based on these nanoindentation results, it appears that the mechanical properties of this PMMA/ HA nanocomposite with $0.1 \% \mathrm{COOH}$-functionalized MWCNTs are compatible for use in bone applications. In this case, in the matrix there is a direct load transfer from the PMMA/HA to the CNTs, where $\mathrm{COOH}$-functionalized CNTs behave like a perfect reinforced material in the matrix nanocomposite. But this is not the case with amine-modified CNTs. That is why the covalently bonded $\mathrm{COOH}$ group functionalized CNTs shows best mechanical properties compare to noncovalently amine-modified/or non-functionalized CNTs, and best suitable for load bearing applications.

From a cellular compatibility standpoint, we probed overall growth potential first. To accomplish this, we used immortalized MG63 cells, which have a high proliferative potential. The growth rate of the cell cultures under control conditions was

Table 1 Average values of hardness and elastic modulus for chemically modified and non-functionalized $0.1 \%$ MWCNTs in the PMMA/HA nanocomposite. The PMMA/HA with $0.1 \% \mathrm{COOH}$-functionalized MWCNTs exhibited a significantly higher hardness $(3.5 \mathrm{GPa})$ and elastic modulus (69 $\mathrm{GPa}$ ) compared to $\mathrm{NH}_{2}$-functionalized and nonfunctionalized MWCNTs/PMMA/HA nanocomposites. The SEM was $\pm 0.60 \mathrm{GPa}$ for the elastic modulus and $\pm 0.05 \mathrm{GPa}$ for the hardness

\begin{tabular}{|c|c|c|}
\hline & $\mathrm{H} / \mathrm{GPa}$ & $\mathrm{E} / \mathrm{GPa}$ \\
\hline HA/PMMA/MWCNTs-COOH & 3.5 & 69 \\
\hline HA/PMMA/MWCNTs--NH ${ }_{2}$ & 0.126 & 5.03 \\
\hline $\begin{array}{l}\text { HA/PMMA/MWCNTs-non- } \\
\text { functionalized }\end{array}$ & 0.363 & 7.61 \\
\hline
\end{tabular}

calculated by counting the number of viable cells in 1200 samples collected from 12 polystyrene wells from day 1 to day 14. Cell cultures exhibited exponential growth with a time constant of 20 $\pm 2 \mathrm{~h}^{-1}$, reaching half of maximal density $\left(1.46 \times 10^{-6} \pm 4.44 \times\right.$ $10^{-4}$ cells $\left.\mathrm{mL}^{-1}\right)$ in $95 \pm 3 \mathrm{~h}\left(r^{2}=0.98132\right)$ as observed in Fig. $4 \mathrm{a}$ (inset). For the nanocomposites, the growth rates of cell cultures seeded on disk-shaped HA/PMMA and HA/PMMA-CNTs samples (Fig. 4b) decreased minimally by only $\sim 2$ and $4 \%$, respectively (Fig. 4a). In addition, the viable cell density
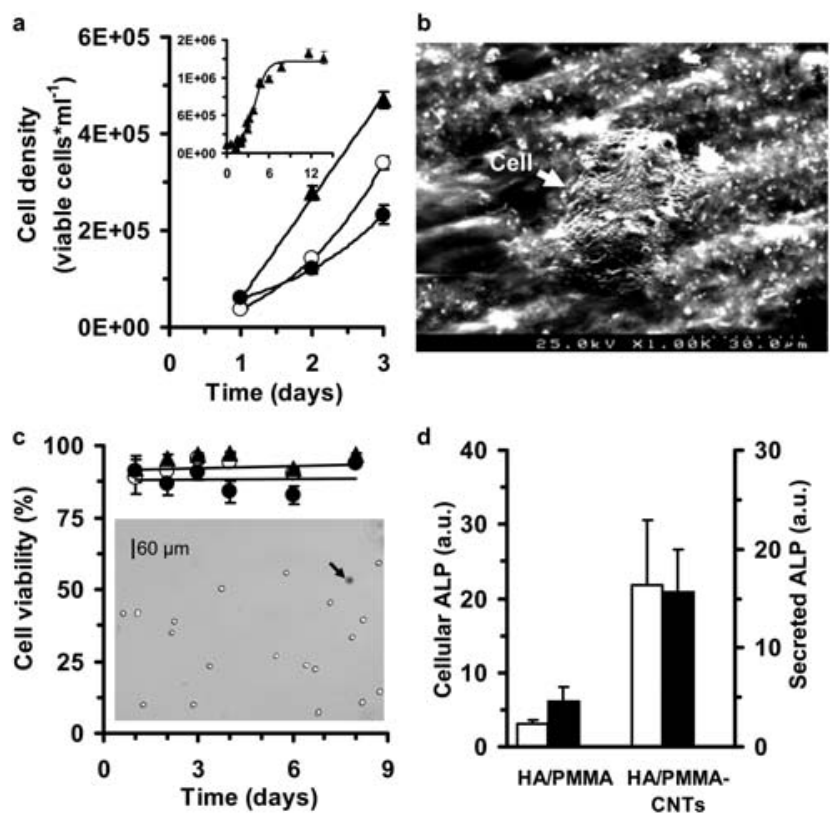

Fig. 4 Cell culture response to the HA/PMMA-CNTs nanocomposite. (a) Temporal evolution of MG63 cell growth on polystyrene ( $\boldsymbol{\Delta})$, HAPMMA (O) and HA-PMMA-0.1\% CNTs ( $)$. The experiments were conducted in triplicate, with each experimental conditions evaluated from 150 images. The images were captured using a Vi-CELL ${ }^{\mathrm{TM}} \mathrm{XR}$ video imaging system for analyzing cells in suspension and the data corresponds to a total number of analyzed cells of 1831 (for polystyrene), 1683 (for HA-PMMA) and 1364 (for HA-PMMA-0.1\% CNTs). The inset shows a growth curve for MG63 cells cultured in 12-well polystyrene culture plates (total number of analyzed images and cells of 800 and 11937, respectively). Experimental data are expressed as viable cell density (mean \pm S.E.). (b) A SEM image of MG63 cell growing on the HA-PMMA-0.1\% CNTs nanocomposite. (c) Cell viability of MG63 cell cultures seeded on distinct surfaces $(\boldsymbol{\Delta}$, polystyrene; $\bigcirc$, HA-PMMA; and - HA-PMMA- $0.1 \%$ CNTs) remained very high during an 8 day incubation period. Experimental data are expressed as the percentage of cells that have not absorbed trypan blue (light cells in the inset image) with respect to the total number of cells in each image. As indicated by the black arrow, cells taking up the trypan blue dye appeared darker. The data points represent the cell viability values (mean \pm S.E.) for each experimental condition, which were analyzed in at least 50 images. (d) Alkaline phosphatase activity (ALP) of MG63 cells solubilized with Triton X-100 (cellular ALP) and in culture medium above each material surface (secreted ALP). Cellular $(\square)$ and secreted ALP (ם) in HAPMMA and HA-PMMA-0.1\% CNTs surfaces were higher than ALP activity on polystyrene surface. Experimental data are expressed as the ratio between the values of ALP on HA-PMMA or HA-PMMA- $0.1 \%$ CNTs versus the polystyrene culture surfaces (mean \pm S.E.). The enzyme activity was normalized by viable cell number for each of the 5 independent assays conducted from day 2 to day 6 after cell seeding. 
determined through direct contact assays repeatedly approached lower maximum values of $4.93 \times 10^{-5} \pm 2.56 \times 10^{-4}$ cells $\mathrm{mL}^{-1}$, for HA/PMMA, and $1.55 \times 10^{-5} \pm 1.37 \times 10^{-4}$ cells $\mathrm{mL}^{-1}$ for HA/PMMA-CNTs compared to the control polystyrene surface, which had $1.01 \times 10^{-6} \pm 3.89 \times 10^{-4}$ cells $\mathrm{mL}^{-1}(n=3)$. Although slower cell growth rates and lower density values reflect decreased capability of MG63 cells to proliferate, the overall cell viability did not change for HA/PMMA or HA/PMMA-CNTs. These results imply that these HA/PMMACNTs composites are likely not toxic, as both materials have high cell viability after culturing for longer periods of time (Fig. 4c). This biocompatibility response is further supported as HA/PMMA-based implants have been used and considered patient safe in orthopedic surgery for more than 35 years. ${ }^{39}$ These results, obtained with cultured MG63 cells confirm that these biomaterials supported cell growth from an osteogenic perspective, which is important with respect to the successful in vivo responses (Fig. 2).

To further probe the in vitro response to the nanocomposites, trypan blue dye exclusion independent assays were carried out between day 1 and day 8 of cell culture $(n=15)$. These results revealed that cell viability remained almost unchanged over the entire experimental period ( $95 \pm 1 \%, n=16410$ cells, control; $92 \pm 1 \%, n=3430$ cells, HA/PMMA; and $89 \pm 2 \%, n=3858$ cells, HA/PMMA-CNTs). No statistically significant $(P=0.733)$ difference was found between the HA/PMMA and HA/PMMACNTs materials when cell viability was assayed directly in multiwell culture plates using a MTT based assay. The MTT assay enables the measurement of cell viability by evaluating the changes in mitochondrial metabolic activity. Changes in the metabolic activity can result in very significant changes in MTT reduction results even when the number of viable cells remains constant. ${ }^{40}$ The MTT assay also revealed lower viability when compared with the trypan blue dye exclusion experiments (Fig. 4c). MTT reduction values from HA/PMMA and HA/ PMMA-CNTs materials at 5 different time points between day 2 and day 6 of culture were $75 \pm 4 \%$ (HA/PMMA) and $79 \pm 10 \%$ (HA/PMMA-CNTs) when compared with corresponding time point control experiments (i.e., polystyrene wells). Under our control conditions, a decline of MTT reduction values normalized by viable cell number was observed from day 1 to day 5 (Fig. S2†). The results on cell growth and viability indicate that HA/PMMA and HA/PMMA-CNTs might anticipate the switch of MG63 cells to a mature phase, since such cell cultures exhibit slower growth rates and lower values of MTT reduction without significant alterations on cell viability when compared to control cell cultures at the same time point.

Bone remodeling is a continuing process of functional and structural alterations at cellular level that gives it mature structure $^{31}$ thus we wanted to examine temporal activity when interfacing our nanocomposites with biological systems. Quantitative analysis of ALP activity (Fig. 4d) and cellular morphometric parameters (Fig. 5) were undertaken with respect to effects of our nanocomposites. The capability of cultured MG63 cells to form matrix vesicles and osteogenic factor-responsive alkaline phosphatase, which are key players in normal bone growth and development and in its repair and regeneration, has been previously demonstrated. ${ }^{41-43}$ Under control conditions, the ALP activity of MG63 remained almost constant at a level of $12 \pm 1$
IU L ${ }^{-1}$ with 8 independent kinetic assays. Stimulation of the ALP activity was also observed when using HA/PMMA and HA/ PMMA-CNTs composites in culture (Fig. 4d). We observed a 3and 4-fold increase of cellular and secreted ALP, respectively, with HA/PMMA when compared to a corresponding time-point control (polystyrene wells); the enzyme activity was normalized by viable cell number in the wells. This result also agreed with previous work where a $60 \%$ increase of cellular ALP was observed after exposing MG63 cells for $24 \mathrm{~h}$ to PMMA particles. ${ }^{44}$ Even more pronounced was evidence showing that the HA/PMMA-CNTs composites induced a 16- and 22-fold increase of secreted and cellular ALP activities, respectively. This finding indicates that this nanocomposite appears to affect osteoblastic maturation by up-regulating early local cellular processes in response to cell-material interactions, supporting our in vivo data (Fig. 2).

From a cell morphology perspective, the profile of MG63 cell cultures showed significant alterations as expected over time (Fig. 5). Fig. 5a is a frequency (percentage) histogram of average cell diameter and circularity observed in day 2 and day 6 after cell seeding under control conditions. The average diameter distribution plots appeared to consist of four peaks ranging from 5 to $30 \mu \mathrm{m}$, reflecting the relative heterogeneity of cell size over time. Forty-four (44\%) of 382 cells were viable with an average diameter of $20 \pm 3 \mu \mathrm{m}$ at day 2 , while the percentage of this cell population with this diameter (average diameter $=20 \pm 4 \mu \mathrm{m}$; $n=2147$ cells) decreased to $35 \%$ by day 4 . This change of the relative frequency of viable cells with $\sim 20 \mu \mathrm{m}$ diameter was accompanied by a higher concentration of smaller cells $(16 \%$ of 382 cells were viable cells with an average diameter of $15 \pm 3 \mu \mathrm{m}$ at day 2 vs. $35 \%$ of 2147 cells were viable cells with an average diameter of $14 \pm 5 \mu \mathrm{m}$ at day 6), as well as by loss of cell circularity $(70 \%$ of 268 cells were viable cells with circularity of $0.89 \pm 0.07$ at day 2 vs. $37 \%$ of 1216 viable cells with a cell circularity of $0.88 \pm 0.09$ at day 6). The HA/PMMA-CNTs shifted both their cell average diameter and circularity distributions toward a morphometric profile (Fig. 5c) that very much resembles the profile of 6 day control cultures (Fig. 5a). It is important to note that the two main peaks remained at the same position; larger cells at $20 \pm 3 \mu \mathrm{m}$ (day 2) and $20 \pm 6 \mu \mathrm{m}$ (day 6), and smaller cells at $14 \pm 4 \mu \mathrm{m}$ (day 2) and $13 \pm 5 \mu \mathrm{m}$ (day 6), respectively.

Cell-substrate interactions have been shown to influence cell differentiation and maturation, due to alteration of biological response, including cytoskeleton organization, signal transduction pathways, and gene expression. For example, the incorporation of nanohydroxyapatite in silicone rubber nanocomposites induced pre-osteoblasts to change from a spherical morphology with a smooth surface toward a flat morphology, large in size with a rough cell surface phenotype. ${ }^{45}$ MG63 cells also seem to respond to surface morphology and stiffness of the substrate by changing cell morphology. ${ }^{46,47}$ In contrast to control cultures, the relative frequency of large and small cells in cultures seeded on the disk-shaped HA/PMMA-CNTs composite remained almost unchanged, with small viable cells representing $45 \%$ (day 2) and $43 \%$ (day 6 ), and large viable cells representing $28 \%$ (day 2) and $37 \%$ (day 6 ) of the total number of cells (316 and 502 cells on day 2 and day 6 , respectively). A shift toward loss of cell circularity was also observed $(29 \%$ of 197 cells were viable 

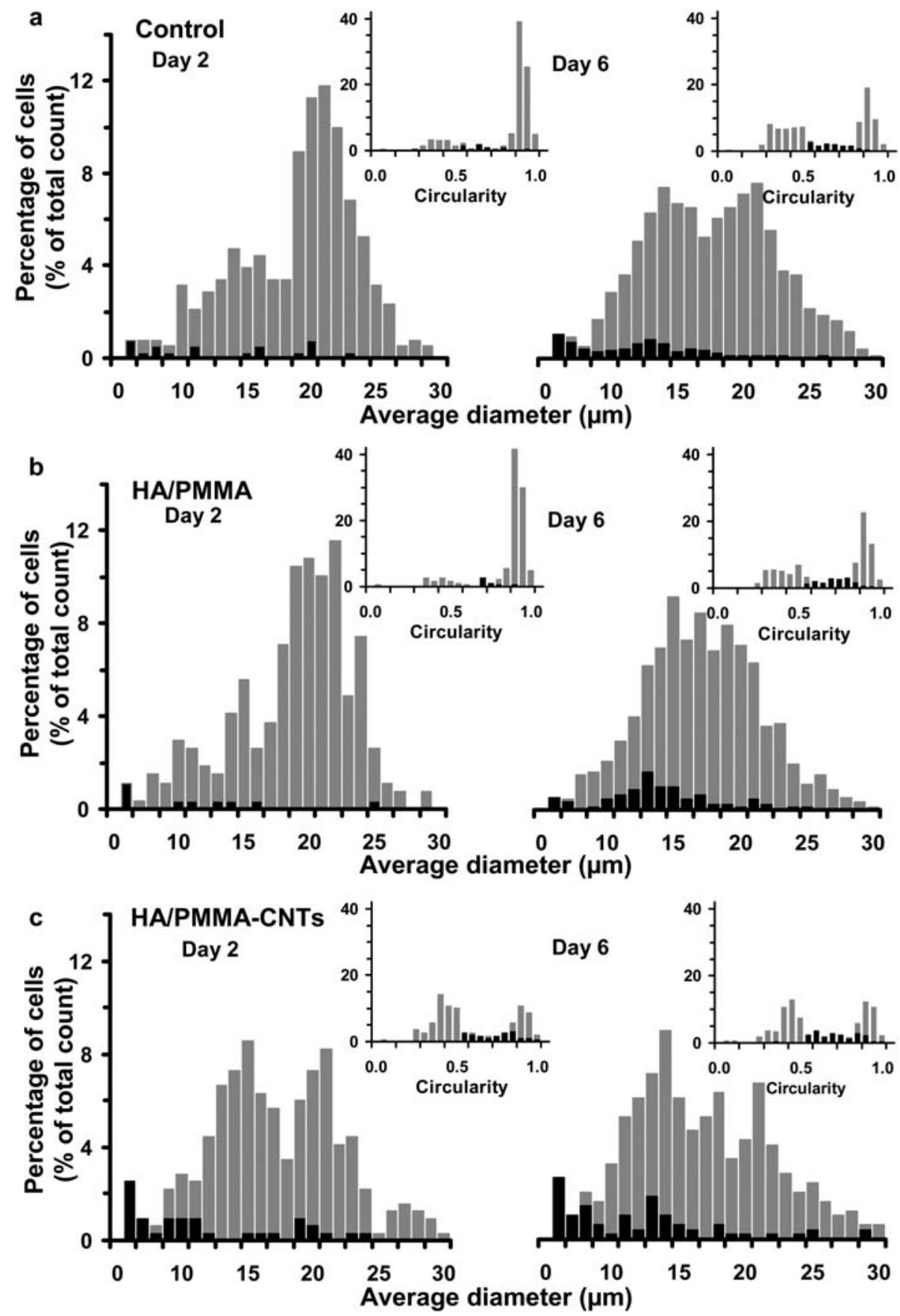

Fig. 5 Morphometric characteristics of MG63 cells during culture indicating significant temporal alterations related to the material interface. (a) Relative frequencies (measured as a percentage) of the average cell diameter and circularity (inset) observed in day 2 (left column) and day 6 (right column) after cell seeding cultured in polystyrene petri dishes (control). Histogram representations of the effects of (b) HA-PMMA and (c) HA-PMMA$0.1 \%$ CNTs surfaces on the cellular morphometric parameters, cell diameter and circularity (inset). The representative percentage histograms were also separated based on viable (grey bars) and dead (black bars) cells. The total number of cells analyzed in panels (a), (b) and (c) were 2529, 1205 and 818 , respectively.

cells with circularity of $0.88 \pm 0.11$ at day 2 vs. $32 \%$ of 526 cells that were viable cells with a cell circularity of $0.89 \pm 0.10$ at day 6). MG63 cell cultures had shown a similar tendency toward precocity through the observed alterations of cellular morphometric parameters in response to HA/PMMA composite (Fig. 5b), however the changes in the respective relative frequency histograms were much less prominent than with HA/PMMA-CNTs (Fig. 5c). Thus, these data appear to confirm that MG63 cells in contact with HA/PMMA-CNTs have more differentiated morphologic features. This in vitro finding is in line with in vivo response (Fig. 2) toward the differentiation of cells due to our nanocomposites. 


\section{Conclusions}

Through our studies with this novel MWCNT nanocomposite, we have found that the use of $\mathrm{COOH}$-functionalized MWCNTs reinforced with PMMA/HA will provide tremendous advancements in the field of regenerative medicine. Of singular importance is the mechano-physical advantage this nanocomposite, which provides for bearing mechanical loads and promoting osteointegration with surrounding bone tissues. These are features not observed with previous materials. ${ }^{12,13}$ Our in vivo and in vitro studies both showed favorable biocompatibility and osteointegration for $0.1 \%$ MWCNTs/PMMA/HA nanocomposites and furthermore, in our in vivo animal studies, new bone extended into the bioactive bone cement. These results confirm that this novel bionanocomposite will be an excellent candidate for bone integration due to its osteoconductivity and biocompatibility. We believe that these results will have applications in a diversity of areas including nanotechnology, biomaterials, and regenerative medicine.

\section{Acknowledgements}

This work was funded by the International Iberian Laboratory of the Nanotechnology; Project NANO/NMed-AT/0115/2007: Nanotechnology for the next generation biomedical implants. This work is integrated in the research and development agreement between University of Aveiro and Carnegie Mellon University. Manoj K Singh and Paula Marques would like to thank the Portuguese Foundation of Science and Technology, Program Compromise with Science and Virgília S. Silva for the scholarship SFRH/BPD/14677/2003.

\section{References}

1 D. E. Discher, P. Janmey and Y. Wang, Science, 2005, 310, 1139.

2 P. R. LeDuc and D. R. Robinson, Adv. Mater., 2007, 19, 3761.

3 P. R. LeDuc and R. R. Bellin, Ann. Biomed. Eng., 2006, 34, 102.

4 L. P. Zanello, B. Zhao, H. Hu and R. C. Haddon, Nano Lett., 2006, 6, 562 .

5 C.-W. Lam, J. T. James, R. McCluskey and R. L. Hunter, Toxicol. Sci., 2004, 77, 126.

6 V. L. Colvin, Nat. Biotechnol., 2003, 21, 1166.

7 P. M. Ajayan and J. M. Tour, Nature, 2007, 447, 1066.

8 J. N. Coleman, U. Khan and Y. K. Gun'ko, Adv. Mater., 2006, 18, 689.

9 M. K. Singh, T. Shokuhfar, J. Gracio, A. C. M. Sousa, J. Fereira, H. Garmestani and S. Ahzi, Adv. Funct. Mater., 2008, 18, 694.

10 P. Rimessi, P. Sabatelli, M. Fabris, P. Braghetta, E. Bassi, P. Spitali, G. Vattemi, G. Tomelleri, L. Mari, D. Perrone, A. Medici, M. Neri, M. Bovolenta, E. Martoni, N. M. Maraldi, F. Gualandi, L. Merlini, M. Ballestri, L. Tondelli, K. Sparnacci, P. Bonaldo, A. Caputo, M. Laus and A. Ferlini, Mol. Ther., 2009, 17(5), 820.

11 W. A. Curtin and B. W. Sheldon, Mater. Today, 2004, 7, 44.

12 C. I. Vallo, G. A. Abraham, T. R. Cuadrado and J. S. Roman, J. Biomed. Mater. Res., 2004, 70, 407.

13 M. A. McGee, D. W. Howie, K. Costi, D. R. Haynes, C. I. Wildenauer, M. J. Pearcy and J. D. McLean, Wear, 2000, 241, 158.

14 M. M. Stevens, Mater. Today, 2008, 11, 18.
15 P. X. Ma, Mater. Today, 2004, 7, 30.

16 Y. Usui, Y. K. Aoki, N. Narita, N. Murakami, I. Nakamura, K. Nakamura, N. Ishigaki, H. Yamazaki, H. Horiuchi, H. Kato, S. Taruta, Y. A. Kim, M. Endo, N. Saito, Small, 4, p. 240.

17 S. Dimitrievska, J. Whitfield, S. A. Hacking and M. N. Bureau, J. Biomed. Mater. Res., 2009, 91A, 37.

18 Y. Zho and F. Stoddart, Acc. Chem. Res., 2009, 42, 1161.

19 S. B. Kim, Y. J. Kim, T. L. Yoon, S. A. Park, I. H. Cho, J. K. Eun, I. A. Kim and J. Shin, Biomaterials, 2004, 25, 5715.

20 S. Gustafsson, L. K. L. Falk, E. Liden and E. Carlstrom, Ceram. Int., 2008, 34, 1609.

21 B. Bhushan, Philos. Trans. R. Soc. London, Ser. A, 2008, 366, 1499.

22 W. C. Oliver and G. M. Pharr, J. Mater. Res., 1992, 7, 1564.

23 I. R. Dias, C. A. Viagas, J. T. Azevedo, E. M. Costa, P. Lourenco, A. Rodrigues and A. S. Cabrita, Lab. Anim., 2008, 42, 465.

24 J. D. Brancroft, A. Stevens, Theory and practice of histological techniques. Edinburgh: Churchill Livingstone, 1996, 99-211.

25 M. L. Schipper, N. Nakayama-Ratchford, C. R. Davis, N. W. S. Kam, P. Chu, Z. Liu, X. Sun, H. Dai and S. S. Gambhir, Nat. Nanotechnol., 2008, 3, 216.

26 A. Billiau, V. G. Edy, H. Heremans, J. Van Damme, J. Desmyter, J. A. Georgiades and P. De Somer, Antimicrob. Agents Chemother., 1977, 12, 11.

27 M. S. Burstone, Ann. N. Y. Acad. Sci., 1960, 85, 431.

28 A. Spreafico, B. Frediani, C. Capperucci, F. Chellini, A. Paffetti, C. D'Ambrosio, G. Bernardini, R. Mini, G. Collodel, A. Scaloni, R. Marcolongo and A. A. Santucci, Proteomics, 2006, 6, 3520.

29 S. J. Yarram, C. Tasman, J. Gidley, M. Clare, J. R. Sandy and J. P. Mansell, Mol. Cell. Endocrinol., 2004, 220, 9.

30 A. Tampieri, M. Sandri, E. Landi, G. Celotti, N. Roveri, M. MattioliBelmonte, L. Virgili, F. Gabbanelli and G. Biagini, Acta Biomater., 2005, 1, 343.

31 K. Henriksen, A. V. Neutzsky-Wulff, L. F. Bonewald and M. A. Karsdal, Bone, 2009, 44, 1026.

32 M. P. Yavropoulou and J. G. Yovos, J Musculoskelet Neuronal Interact, 2008, 8, 204.

33 L. Suna, G. L. Warrena, J. Y. O'Reillya, W. N. Everetta, S. M. Leea, D. Davisb, D. Lagoudasb and H.-J. Suea, Carbon, 2008, 46, 320.

34 C. C. P. M. Verheyen, J. R. Wijn, C. A. Blitterswijk and K. Groot, J. Biomed. Mater. Res., 1992, 26, 1277.

35 R. E. Neuendorf, E. Saiz, A. P. Tomsia and R. O. Ritchie, Acta Biomater., 2008, 4, 1288.

36 J. Zhu, H. Peng, F. Rodriguez-Macias, J. L. Margrave, V. N. Khabashesku, A. M. Imam, K. Lozano and E. V. Barrera, Adv. Funct. Mater., 2004, 14, 643.

37 D. M. Ebenstein and L. A. Pruitt, Nanotoday, 2006, 1, 26.

38 J. Konnerth, A. Jager, J. Eberhardsteiner, U. Muller and W. Gindl, J. Appl. Polym. Sci., 2006, 102, 1234.

39 J. Charnley, Clin Orthop., 1970, 72, 7.

40 D. Gerlier and N. Thomasset, J. Immunol. Methods, 1986, 94, 57.

41 B. D. Boyan, Z. Schwartz, L. F. Bonewald and L. D. Swain, J. Biol. Chem., 1989, 264, 11879 .

42 C. Morris, J. Thorpe, L. Ambrosio and M. Santin, J. Nutr., 2006, 136, 1166.

43 H. M. Huang, S. Y. Lee, W. C. Yao, C. T. Lin and C. Y. Yeh, Clin. Orthop. Relat. Res., 2006, 447, 201.

44 C. H. Lohmann, D. D. Dean, G. Köster, D. Casasola, G. H. Buchhorn, U. Fink, Z. Schwartz and B. D. Boyan, Biomaterials, 2002, 23, 1855.

45 W. W. Thein-Han, J. Shah and R. D. Misra, Acta Biomater., 2009, 5, 2668.

46 D. Docheva, D. Padula, C. Popov, W. Mutschler, H. ClausenSchaumann and M. Schieker, J. Cell. Mol. Med., 2008, 12, 537.

47 M. Mattioli-Belmonte, G. Vozzi, K. Kyriakidou, E. Pulieri, G. Lucarini, B. Vinci, A. Pugnaloni, G. Biagini and A. Ahluwalia, J. Biomed. Mater. Res., 2008, 85A, 466. 